\title{
Ideas for How to Take Wicked Problems Seriously
}

\author{
Kyle Powys Whyte $\cdot$ Paul B. Thompson
}

Accepted: 22 September 2011/Published online: 8 October 2011

(C) Springer Science+Business Media B.V. 2011

Too often we hear that environmental and agricultural problems are just about there being too many people on the planet, or consumers improving their buying habits, or getting the right ethics or virtues or the best science. Framing matters within a single solution, or "panacea," as Ostrom et al. refer to it (Ostrom et al. 2007), assumes we already know well in advance that the problems can be understood so compactly. Yet it makes little sense to assume that there are easily identifiable drivers for climate change, animal welfare, natural resource management, and sustainable agriculture or engineering, among many other complex problem areas that we face today. Each of these subjects is problematic in multiple ways. Each of them involves interaction between diverse forms of human conduct and complicated biological processes that are not fully understood. The distinguished ecologist Donald Ludwig has suggested that such problems cannot be addressed through the paradigm of management and are best approached as wicked (Ludwig 2001).

Ludwig was referring to a 1973 paper in the urban planning literature by Horst Rittel and Melvin Webber. Wicked problems are not simply complex. According to Rittel and Webber, there are ten aspects to these special challenges that should be respected and grappled with by those who seek to respond to them. They begin by noting that every way of formulating a problem (e.g., as economic, as environmental, as social, etc.) implies some solutions (e.g., carbon trading, regulation, international aid, etc.) and excludes other solutions from being considered. The ontology of problem formulation has implications for the epistemology of problem response. Thus, to describe climate change as an economic problem means that one has already limited oneself to particular economic solutions to addressing it. Because proposed solutions are so closely tied to problem formulations, disagreements among stakeholders who foresee themselves as being impacted differently by the solutions can take the form of

K. P. Whyte $(\bowtie) \cdot$ P. B. Thompson

Department of Philosophy, Michigan State University, 503 S. Kedzie Hall, East Lansing,

MI 48824, USA

e-mail: kwhyte@msu.edu 
ontological debates. Unlike problems where there is little disagreement about its basic formulation, wicked problems are characterized by deep ambiguity in the ontological assumptions and metaphysical categories used in their articulation.

Second, while it is often reasonably clear whether one has a problem or not, there is no clearly foreseeable point when we know the wicked problem will stop. When does the problem of climate change stop? When do we know that we have done enough to put climate change aside as a matter of concern? These are impossible questions to ask of climate change; our efforts to mitigate and adapt to climate change must get underway without getting to rely on a stopping rule. The lack of clear criteria for solutions may reflect ambiguity in problem formulation, but may also reflect value-laden elements in our understanding of key phenomena. Thus third, there can be no absolute perspective on the truth or falsity of any proposed solutions to a wicked problem. Consider intensive versus smallholder agriculture. While agriculture is often conceptualized as a technical domain open to scientific inquiry, there is no way of concluding which one is the "true" system of food production. If one favors intensive agriculture, then those stakeholder's whose interests are not served by it see themselves as worse off within one's vision, and vice versa. With every proposed solution, stakeholders see themselves as better or worse off, and one cannot evaluate when it is correct for someone else to be worse off because of what will make oneself better off. Truth and falsity have a limited role in wicked problems, where the multiple stakeholders' perspectives on their being better or worse off in relation to various proposed interventions are tightly linked with alternative approaches to scientific and technological investigation.

Fourth, there are no ultimate tests for whether a particular solution that has been applied has solved the wicked problem. Consider what would happen if agriculture was all converted to organic production. Though many of us may favor that, how do we actually know what ripple effects will grow out of government policies for organics across social and ecological systems and many generations? How can we develop a test that will adjust for all of these possible effects? Fifth, a characteristic mark of wicked problems is that any proposed response will have irreversible consequences. Applied solutions to wicked problems cannot be undone; they leave permanent marks. Geoengineering technologies for controlling climate cannot be implemented and then stopped if they are not doing what we want them to do. Their climactic effects, not to mention the investment in research and infrastructure, likely involve massive social and ecological changes that cannot be reversed at any near point in the future. Wicked problems cannot be tinkered with through low stakes trial and error experimentation.

Sixth, wicked problems admit of innumerable possible solutions. Will we ever know whether we have exhausted all possibilities for climate mitigation and adaptation? Seventh, every wicked problem is unique; that is, one cannot rely on some precedent of the exact same problem in the past. There are numerous differences. Sustainable forestry today cannot look back to the successes and failures of Pinchot era forestry. Though historical background is critical for approaching wicked problems, it is not because there are straightforward relationships between historical and present circumstances. Forestry today involves drastically different social, political, ecological, cultural, agricultural, and physical (among others) circumstances than the early 
twentieth century. Eighth, every wicked problem can ultimately be seen as a symptom of other wicked problems. Sustainable agriculture problems are symptoms of climate change; climate change is a symptom of sustainable agriculture problems; sustainable agriculture problems are symptoms of animal welfare, water quality management, biodiversity, and other wicked problems.

Ninth, as a consequence of ontological ambiguities and epistemic uncertainties, the causes of wicked problems can be explained in numerous ways. Consider globalization as a cause of biodiversity loss. This cause can be explained in terms of industrialization, individual greed, social oppression, and tradeoffs, yet also in the language of scientific and engineering explanations of the ecological and physical changes involved; there are numerous explanations within these technical perspectives as well. Dan Sarewitz has characterized this aspect of wicked problems as "an excess of objectivity" (Sarewitz 2004). Tenth, those who have the power to advance policy and research on wicked problems have no right to be wrong. That is, there is no forgiveness or understanding for those whose actions lead to grievous errors no matter how much we learn from them. Systems of reward, criticism, and blame operate much differently in wicked problems than in professional disciplines.

Given these ten aspects, some may see the idea of wicked problems as mainly just expressing the daunting reality of the challenges we face today. However, we believe that the metaphysical, epistemological, and ethical implications of the wicked problem idea are more far reaching. It really serves as one game changing heuristic that we can use to improve how academic research and education should be crafted and evaluated to respond to the complex problems that matter to us. If the problems we seek to address admit of wicked aspects, then it is unlikely that our disciplinary institutions like departments, peer review processes, research methods, academic audiences, and relationship to policy development are adequate by themselves for supporting our efforts. In fact, academic success in environmental and agricultural research, whether in the humanities, sciences, or engineering disciplines, is likely far easier to claim for ourselves when we openly ignore the wickedness of the problems we are addressing in front of our colleagues and audiences. Promoting panaceas, even very naïve ones, can garner public and disciplinary recognition, publication, and career advancing notoriety.

C. West Churchman, a philosopher who spent most of his career working with city planners and businesses, best captured this issue in the 1960s regarding the ethical obligations of operations researchers (OR) to managers in the context of wicked problems, which we quote at length:

[W]hoever attempts to tame a part of a wicked problem, but not the whole, is morally wrong.

Such a moral principle would appear to be ridiculous to many a management scientist, who has been brought up to believe that he should only tackle "feasible" problems. For him to tame the whole of a wicked problem is not feasible, and hence the moral principle tells him to do something that his teachers told him was wrong. Of course, none of his teachers was ever able to tell him what "feasible" means, because that's a wicked problem; but nevertheless, the student of management science usually develops his own 
idea in a short span of experience. For those who believe they can identify the feasible, there is the saving moral principle of honesty. If I tell you honestly what I have done, so goes the story, then you need not be deceived. So the management scientist, being honest, says to the manager: "Look, I've not tamed the whole problem, just the growl; the beast is still as wicked as ever." This is how morality aids morality in the arena of right and wrong. But there is a sneaking suspicion that the answer is a weak one. It takes more than a verbal caveat to inform the manager that the OR solution is incomplete. The model, or the large computer program, plus expensive months of data collection and analysis, must give the impression that most of the wicked problem has been tamed. Dishonesty, as any con-man knows, can be created in the environment of complete, outspoken frankness and honesty. What seems to emerge is not a moral reprimand but rather a moral problem of the profession, a wicked moral problem. To what extent are we morally responsible to inform the manager in what respect our "solutions" have failed to tame his wicked problems? Does "inform" merely mean that we clear ourselves legally, or does it mean that we attempt to enter into a deep, mutual understanding of the untamed aspects of the problem? (Churchman 1967, B-142)

What guidance can Churchman's words give us as researchers and educators who address wicked problems within our professions?

The authors in this special section of Journal of Agricultural and Environmental Ethics take this question very seriously. They seek to use the wicked problems framework as a heuristic for how to transform research, education, expertise, and disciplinary praxis. Each article is authored by at least one philosopher; one paper is a collaboration between two sustainability scientists and a philosopher. The articles came together in response to a 2009 call for papers that we issued for recent research on wicked problems and the environment. We felt strongly that there should be more available scholarship on the value and use of the wicked problems framework. The result is a collection of articles that impact how we understand policy analysis, adaptive management, sustainability science, sustainability education, and environmental philosophy.

In "Ways of Wickedness: Analyzing Messy Problems with Messy Tools," Bryan Norton presses the question whether there are possibilities for rational discourse leading to cooperative action in the face of wicked problems. He argues that the wicked problems framework suggests better ways of pursing policy analyses using the language of boundary critique. In "Sustainable Engineering Science for Resolving Wicked Problems," Thomas Seager, Evan Selinger, and Arnim Wiek take up the challenges of the wickedness of sustainability problems for envisioning reform of current engineering science and technology practices. They offer a new conception of sustainable engineering science that involves ethical awareness, anticipatory and adaptive approaches, and interactional expertise. Paul Thompson and Kyle Powys Whyte explore whether the wicked problems framework should be taken seriously by environmental philosophers. They argue that wicked problems open up opportunities for philosophers to reimagine their skills in collaborative contexts that will be particularly important for environmental, agricultural, and sustainability problems. 


\section{References}

Churchman, C. W. (1967). Wicked problems. Management Science, 14(4), B141-B142.

Ludwig, D. (2001). The era of management is over. Ecosystems, 4(8), 758-764. doi:10.1007/ s10021-001-0044-X.

Ostrom, E., Janssen, M. A., \& Anderies, J. M. (2007). Going beyond panaceas. Proceedings of the National Academy of Sciences, 104(39), 15176-15178. doi:10.1073/pnas.0701886104.

Rittel, H. W. J., \& Webber, M. M. (1973). Dilemmas in a general theory of planning. Policy Sciences, 4, $155-169$.

Sarewitz, D. (2004). How science makes environmental controversies worse Enviromental Science \& Policy, 385-403. 